\title{
The Teratogenicity of Cadmium Chloride in Two Stocks of Wistar Rats ${ }^{1}$
}

\author{
MASON BARR, JR. \\ Department of Pediatrics and Communicable Diseases, University of \\ Michigan, Ann Arbor, Michigan 48104
}

\begin{abstract}
The teratogenicity of cadmium chloride $\left(16 \mu \mathrm{M} / \mathrm{kg} \mathrm{Cd}^{++}\right)$was studied in Wistar rats from two commercial sources. Subcutaneous cadmium was not teratogenic. Intraperitoneal cadmium was highly teratogenic in both stocks when given on day 9,10 , or 11 of gestation. There were marked differences between the two stocks in fetal mortality and the incidence and types of malformations produced. Cadmium on day 9 produced an attenuation of the abdominal wall in $13-16 \%$ of the term fetuses. In one stock of rats, cadmium on day 10 produced reduction deformities of one forelimb similar to the previously reported acetazolamide syndrome in rats.
\end{abstract}

In recent years the presence of cadmium as an environmental contaminant has aroused concern because of its marked toxicity in man (Flick et al., '71). Both acute and chronic forms of cadmium poisoning have been reported in man but the role of cadmium in human teratogenesis remains unresolved. In mice orally administered cadmium salts produce fetal mortality, runting, and malformation (Schroeder and Mitchener, '71). Intravenous cadmium sulfate in hamsters produces malformation, particularly of the face (Mulvihill et al., '70).

Preliminary studies in this laboratory have shown that intraperitoneal cadmium sulfate is teratogenic in rats (Barr, '72), but the spectrum of malformations is quite different from that reported in hamsters. Further investigation showed that both the incidence and variety of malformations caused by cadmium in rats depend a great deal on the particular stock of animals used. This study reports the teratogenic effects of cadmium chloride in two stocks of Wistar rats.

\section{MATERIALS AND METHODS}

Virgin female and male Wistar rats were purchased from two commercial sources and designated as the $\mathrm{C}$ and $\mathrm{S}$ stocks. ${ }^{2}$ The rats were maintained in one room with a controlled environment and allowed Rockland rat diet and tap water ad libitum. Nonpregnant females were housed
4-6 per cage; pregnant females were caged individually. Males and females were bred in pairs overnight and the presence of sperm in a vaginal smear was assumed to indicate day 0 of pregnancy.

The dose used in this study was $16 \mu \mathrm{M} /$

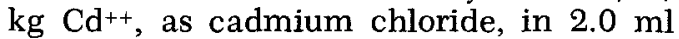
isotonic saline. Injections were given intraperitoneally (ip) and in some cases subcutaneously (sc). Controls received ip injections of isotonic saline. All injections were given at 8-9 AM on day 9,10 , or 11 of gestation. Six rats were bred successfully 14-31 days after receiving an ip dose of cadmium chloride.

On day 21 of gestation pregnant rats were killed by ether overdose and the number and intrauterine positions of fetuses and resorption sites were noted. The fetuses were separated from their placentas, cleaned, and promptly weighed. After fixation in Bouin's fluid the fetuses were examined for malformation by the razor-blade dissection technique (Wilson, '65).

In the statistical treatment of the data, means, errors, and rates were calculated from subgroup totals and from litter means. There was little difference between the results of the two methods of calculation and the results reported are those calculated from subgroup totals, ignoring

\footnotetext{
Received Dec. 7, '72. Accepted Mar. 5, '73.

I Supported by NIH grant 5-S01-RR05383 to the University of Michigan.

2 C stock from Carworth, New City, N. Y., S stock from Simonsen Laboratories, Gilroy, California.
} 
litter groupings. Mean implantation number and mean fetal weight differences were tested for statistical significance by $t$ tests. The significance of associations among malformations and of differences in incidence of malformations and resorptions were tested by calculating $\chi^{2}$ (with Yate's correction) from $2 \times 2$ contingency tables.

\section{RESULTS}

Preliminary study showed that doses of 7-18 $\mu \mathrm{M} / \mathrm{kg} \mathrm{Cd} \mathrm{Cd}^{++}$body weight were teratogenic when given on day 9, 10, or 11 . Excess fetal mortality and malformation were not found after administration of cadmium on day $6,7,8$, or 12 . Doses in excess of $22 \mu \mathrm{M} / \mathrm{kg} \mathrm{Cd}{ }^{++}$often killed pregnant rats. Following ip cadmium, pregnant rats uniformly lost weight for 1-2 days and then took 2-4 days more to return to or exceed their injection-day weight. However, by day 21 , injected rats did not differ significantly from control rats in total maternal weight gain. Rats that received cadmium sc showed little or no weight loss following injection. There were no significant differences in maternal weight gain between the $C$ and $S$ stocks as measured on days 7,14 , and 21 of gestation.

The day of saline injection had no effect on control fetal mortality or weight, and therefore all control litters of a given stock were treated as one group. Similarly no differences in fetal mortality or weight were observed among the rats receiving sc cadmium, and these litters were also treated as single groups (table 1). Following sc cadmium fetal mortality and malformation rates were unchanged from control values. In the $\mathrm{C}$ stock mean fetal weight of the treated litters was not signficantly different from the controls. In the $\mathrm{S}$ stock mean fetal weight of the treated litters was higher $(P<0.05)$ than the controls.

Among the animals receiving ip cadmium during gestation there was a marked difference in fetal mortality between the stocks. The $\mathrm{S}$ stock had a much higher fetal mortality than the $C$ stock, regardless of the day of injection. Fetal mortality in the treated $\mathrm{C}$ stock was not significantly different from the controls (table 1). Fetal weight was invariably depressed following ip cadmium. The $\mathrm{C}$ stock litters showed a progressively more severe fetal growth retardation after day-9 to -11 injection, whereas the $S$ stock litters had maximal retardation following day 10 injection (table 1).

Ip cadmium chloride was teratogenic in both stocks of rats when given on day

TABLE 1

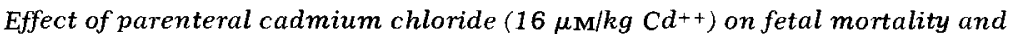
mean fetal weight in two stocks of Wistar rats

\begin{tabular}{|c|c|c|c|c|c|}
\hline $\begin{array}{l}\text { Treatment } \\
\text { subgroup }\end{array}$ & Litters & Fetuses & $\begin{array}{l}\text { Implantations } \\
\text { per litter }\end{array}$ & $\begin{array}{c}\text { Resomption } \\
\text { rate }\end{array}$ & $\begin{array}{c}\text { Fetal weight } \\
\text { (g) }\end{array}$ \\
\hline \multicolumn{6}{|c|}{ C stock } \\
\hline $\begin{array}{l}\text { ip day } 9 \\
\text { ip day } 10 \\
\text { ip day } 11 \\
\text { sc day } 9-11 \\
\text { Control }\end{array}$ & $\begin{array}{r}8 \\
10 \\
12 \\
7 \\
34\end{array}$ & $\begin{array}{r}121 \\
123 \\
172 \\
87 \\
403\end{array}$ & $\begin{array}{l}15.9^{1} \\
13.8^{1} \\
15.3^{1} \\
13.1^{1} \\
12.8\end{array}$ & $\begin{array}{r}4.7 \\
10.9 \\
6.5 \\
5.4 \\
7.4\end{array}$ & $\begin{array}{l}4.41 \pm 0.04 \\
4.15 \pm 0.04 \\
3.91 \pm 0.04 \\
5.03 \pm 0.04 \\
5.10 \pm 0.01\end{array}$ \\
\hline \multicolumn{6}{|c|}{ S stock } \\
\hline $\begin{array}{l}\text { ip day } 9 \\
\text { ip day } 10 \\
\text { ip day } 11 \\
\text { sc day } 9-11 \\
\text { Control }\end{array}$ & $\begin{array}{r}8 \\
9 \\
10 \\
11 \\
11\end{array}$ & $\begin{array}{r}86 \\
85 \\
97 \\
119 \\
134\end{array}$ & $\begin{array}{l}13.3 \\
13.2 \\
12.1 \\
11.3 \\
12.5\end{array}$ & $\begin{array}{c}18.9^{1} \\
28.6^{1} \\
19.8^{1} \\
4.0^{1} \\
2.2\end{array}$ & $\begin{array}{l}4.77 \pm 0.061 \\
4.30 \pm 0.05 \\
4.52 \pm 0.04 \\
5.19 \pm 0.04 \\
5.07 \pm 0.03\end{array}$ \\
\hline ip preconception 3 & 6 & 74 & 13.2 & 6.3 & $5.30 \pm 0.06$ \\
\hline
\end{tabular}

1 Significantly different from corresponding control, $p<0.01$.

2 Significantly different from corresponding control, $P<0.05$

3 Mixed $C$ and $S$ stocks given ip cadmium 14-31 days prior to conception. 
9,10 , or 11 of gestation (table 2). Anophthalmia or microphthalmia on one or both sides was found in greatest number after cadmium on day 9. Few of the day 10treated fetuses had eye malformations. Dysplastic or absent ears were found in both stocks only after day-9 treatment. Malformation of the face, which is characteristic of cadmium teratogenesis in hamsters, was virtually absent in these rats; only three facial malformations were seen. Hydrocephaly was observed frequently after cadmium treatment on days 9 and 11 , but not after treatment on day 10. There were also four cases each of encephalocele and exencephaly distributed between the $\mathrm{C}$ and $\mathrm{S}$ stocks in the day-9 and -11 subgroups.

A peculiar malformation of the abdominal wall was observed, particularly following day-9 cadmium. This defect was characterized by an extreme attenuation of the abdominal wall, to less than $0.5 \mathrm{~mm}$ in thickness. Usually these abdominal walls were paper-thin and ballooned outward but there was no evidence of increased intraabdominal pressure or visceromegaly. In addition to the thinness, no distinction could be made between cutaneous and musculofascial layers. The abdominal wall was typically attenuated on one or both lateral aspects but occasionally the thinning extended to the midventral surface as well. Deficiency of the abdominal wall in the $C$ stock was significantly $(P<0.05)$ associated with leftsided umbilical artery, ear dysplasia, undescended testes, and renal agenesis. None of these associations was significant in the S stock, nor were there associations between other malformations and thin abdominal walls in either stock.

Single cases of absence of the left leaf of the diaphragm with herniation of the liver into the thorax were found in the C stock/day-10 and -11 and the S stock/ day-9 subgroups. In contrast this deformity was seen in $47 / 85(55 \%)$ of the fetuses in the $\mathrm{S}$ stock/day-10 subgroup. Anal atresia, not accompanied by gross abnormality of the gut, was found in $21 \%$ of the fetuses in the $\mathrm{S}$ stock/day-10 subgroup. Among fetuses with anal atresia there were significant $(P<0.05)$ associations with diaphragmatic hernia, left-sided umbilical artery, hydronephrosis, and tail malformation, especially absent tail. Only five cases of anal atresia were found among the $\mathrm{C}$ stock fetuses, all following day-11 treatment. Hydronephrosis was seen in fetuses from all experimental subgroups receiving ip cadmium during gestation. It was characterized by a dilated renal pelvis and absence of a papilla in the cross-sectioned kidney. Many kidneys had a dilated pelvis and a small, blunted papilla, but about $10 \%$ of the control fetuses also had this "apparent hydro-

TABLE 2

Malformation rates (\%) in term fetuses, by day of intraperitoneal cadmium chloride administration, in two stocks of Wistar rats

\begin{tabular}{|c|c|c|c|c|c|c|}
\hline \multirow{2}{*}{ Abnormality 1} & \multicolumn{3}{|c|}{ C stock } & \multicolumn{3}{|c|}{ S stock } \\
\hline & 9 & 10 & 11 & 9 & 10 & 11 \\
\hline \multicolumn{7}{|l|}{ Anophthalmia or } \\
\hline microphthalmia & $61.2^{3}$ & 4.9 & 0 & 31.4 & 1.2 & 0 \\
\hline Dysplastic ears & 9.9 & 0 & 0 & 16.3 & $\mathbf{0}$ & 0 \\
\hline Hydrocephaly & 29.8 & 0 & 33,1 & $55.8^{3}$ & 0 & 28.9 \\
\hline Diaphragmatic hernia & 0 & 0.8 & 0.6 & 1.2 & $55.3^{3}$ & 0 \\
\hline Thin abdominal wall & 16.5 & 4.9 & 1.2 & 12.8 & 0 & 1.0 \\
\hline Undescended testes & 13.3 & 4.6 & $65.9^{3}$ & 2.3 & $18.6^{3}$ & 2.0 \\
\hline Dysplastic forelimbs & 0 & 0 & 1.2 & 1.2 & $29.4^{3}$ & 2.0 \\
\hline Left & 0 & 0 & 0.6 & 0 & $28.2^{3}$ & 1.0 \\
\hline Right & 0 & 0 & 1.2 & 1.2 & 1.2 & 1.0 \\
\hline Dysplastic tail & 0.8 & 6.5 & $95.9^{3}$ & 7.03 & 30.63 & 74.2 \\
\hline Anal atresia & 0 & 0 & 2.9 & 2.3 & $21.2^{3}$ & 0 \\
\hline Hydronephrosis & 7.4 & 10.6 & 13.4 & 14.0 & 4.7 & 5.2 \\
\hline Left umbilical artery 2 & 14.9 & 13.8 & 11.6 & 9.3 & $29.4^{3}$ & 14.4 \\
\hline
\end{tabular}

1 See text for details of abnormalities.

2 Control and sc-cadmium fetuses had $2.3-3.0 \%$ incidence of left-sided umbilical artery.

3 Significant difference $(P<0.05$ ) between the stocks for given day of cadmium administration. Higher rate is marked. 
nephrosis." Woo and Hoar (72) described such kidneys as a normal finding in about $20 \%$ of normal day-21 rat fetuses. Therefore, in this study these kidneys were regarded as not truly hydronephrotic. Agenesis of the kidney, always unilateral, was found in a small number of fetuses in both stocks following day- 9 cadmium.

Forelimb malformation was observed almost exclusively in the left forelimb following day-10 cadmium in the S stock.

Absence or severe hypoplasia of the postaxial portion of the paw was seen in 21/85 fetuses. Four fetuses had both preand postaxial dysplasia of the paw and reduction deformity of the shaft of the forelimb. Seventeen of the affected fetuses were female; compared to the nonaffected fetuses this was a significant $(P<0.05)$ excess of females. Only three fetuses in the S stock/day-9 and -11 and two in the C stock/day-11 subgroups had forelimb malformation. No forelimb defects were seen in the $\mathrm{C}$ stock animals treated on day 9 or 10 .

Malformation of the tail, ranging from complete absence to tight curling of the tip, was found in a high percentage of the survivors of both stocks following day-11 cadmium. The $\mathrm{C}$ stock was more severely and more frequently affected than the $S$ stock. However, the $S$ stock had significantly $(P<0.05)$ more tail defects after day- 9 and -10 cadmium than did the $C$ stock. The highest incidence $(12 \%)$ of complete absence of the tail was found in the S stock/day-10 subgroup; none of the C stock/day-10 subgroup had absent tails.

Normally in the rat the right umbilical artery persists and the left becomes obliterated during development. In about 2$3 \%$ of normal rats the situation is reversed and the left artery persists. Following ip cadmium there was a marked increase in the incidence of left-sided umbilical artery. In the $\mathrm{C}$ stock left umbilical artery was significantly $(P<0.05)$ associated with thin abdominal wall, dysplastic ears, and undescended testes after day-9 cadmium; with hydronephrosis and malformed tail after day-10 cadmium; and with undescended testes and hydronephrosis after day-11 cadmium. In the S stock left umbilical artery was significantly associated with hydronephrosis, diaphragmatic hernia, malformed tail, anal atresia, and undescended testes after day-10 cadmium.

A single ip dose of cadmium chloride given 14-31 days prior to conception had no effect on either litter size or fetal mortality (table 1). The mean fetal weight of these litters was greater $(P<0.01)$ than the controls. The meaning of this finding is not clear.

\section{DISCUSSION}

The mechanism of cadmium toxicity in mammals has not been established. That the toxicity is inhibited by various agents suggests cadmium is competitive with other cations, especially zinc, for specific enzymes (Flick et al,, '71). Cadmium is concentrated in certain tissues, particularly liver and kidney, and is bound in these tissues in the form of a metalloprotein (Pulido et al., '66; Webb, '72a,b). The relationships among ionic cadmium, protein-bound cadmium, and the production of toxicity have not been elucidated. Webb (72) found that cadmium injected in rats before pregnancy was not mobilized from the maternal liver and kidneys during gestation.

Reported excretion rates of cadmium vary widely but there is agreement that excretion is slow and that tissue retention of cadmium is prominent. Nordberg and Nishiyama (72) calculated that the biological half-life of iv ${ }^{109} \mathrm{Cd}$ in CBA mice was 50 days. Furst et al. (72) reported that, in the first 6 days, urinary excretion of cadmium sulfate by Fischer-344 rats amounted to about $12 \%$ of a sc or im dose and $57 \%$ of an ip dose. It is apparent that there is more rapid mobilization of cadmium into the blood stream and therefore higher blood levels after ip injection than after $s c$ injection. This is consistent with the finding in this study that ip cadmium was teratogenic while sc cadmium was not. Webb ('72b) reported an increased incidence of fetal mortality and malformation in rats following sc injection of cadmium chloride, but the dose (22 $\mu \mathrm{M} / \mathrm{kg} \mathrm{Cd}^{++}$) was considerably higher than that used in this study $(16 \mathrm{M} / \mathrm{kg}$ $\left.\mathrm{Cd}^{++}\right)$.

Paŕizek ('65) reported that cadmium late in gestation produced marked histological damage of the placenta and toxemia in the pregnant rat. The placentas 
of fetuses in this study showed no obvious morphological or weight changes when compared to the controls. Late in gestation cadmium may not reach the fetus. Berlin and Ullberg ('63) were unable to demonstrate that ${ }^{109} \mathrm{Cd}$ crossed the mouse placenta late in gestation. Prior to formation of the chorioallantoic placenta cadmium does reach the fetus. Ferm et al. (69) found significant radioactivity in the fetus $24 \mathrm{~h}$ after ${ }^{109} \mathrm{Cd}$ was given iv to pregnant hamsters on the 8th day. Whether or not cadmium reaching the fetus is concentrated in affected sites or in any fetal tissues is unknown. Ferm et al. ('69) showed that $96 \mathrm{~h}$ after administration the concentration of ${ }^{109} \mathrm{Cd}$ in the fetus had decreased some 60 -fold from the concentration present $24 \mathrm{~h}$ after injection. Thus there was a net elimination of ${ }^{109} \mathrm{Cd}$ from the fetus beyond the diminution in concentration due to increase in fetal mass. Appreciable amounts of ${ }^{109} \mathrm{Cd}$ were found in the hamster yolk-sac placenta and this may bear on the problem of how the fetus eliminates cadmium from its body.

Variations of response to teratogens in different strains of mice have been well documented (Kalter, '65). In the case of rats the source of animals is often not identified or given consideration as a source of variation in results. From comparison of the two stocks of rats used in this study it is evident that there is considerable variation in teratogenic response among Wistar rats. A prior study of the toxicity of cadmium sulfate in the S stock (Barr, '72) provides corroboration of the differing sensitivity of the $\mathrm{C}$ and $\mathrm{S}$ stocks to cadmium-induced malformation. Certain characteristic malformations, especially diaphragmatic hernia, left forelimb reduction deformity, and the anal atresia, found in the $\mathrm{S}$ stock/day-10 subgroup after cadmium chloride were also noted in the comparable subgroup treated with cadmium sulfate. Such defects were rare or nonexistent in the $\mathrm{C}$ stock.

The thin abdominal walls found in these rats following ip cadmium were reminiscent of the deficient abdominal muscle syndrome in humans. The association of abdominal wall deficiency with undescended testes and renal malformation in $\mathrm{C}$ stock rats resembled the association of abdominal wall deficiency with undescended testes and dilated urinary tract in humans. However, the analogy between the condition in rats and humans cannot be carried too far because unlike humans there was no excess of affected male rat fetuses and association of thin abdominal wall with genitourinary malformation was not evident in the $\mathrm{S}$ stock. Injection of cadmium sulfate in the $S$ stock produced a higher incidence of thinned abdominal wall than is reported here (43 vs. $16 \%$ ) (Barr, '72). This was so despite the fact that the dose of cadmium was often less than the $16 \mu \mathrm{M} / \mathrm{kg}$ $\mathrm{Cd}^{++}$used in this study. Most of the malformations listed in table 2 occurred with greater frequency after cadmium sulfate than after cadmium chloride. Although direct comparison of the two studies is difficult because of some variation in experimental design there is evidence that in general cadmium sulfate may be more teratogenic than cadmium chloride in equimolar doses.

Layton and Hallesy ('65) discovered that acetazolamide produced a syndrome in rats characterized by reduction deformities of the postaxial portion of the right forelimb. Scott et al. (72) found a significant excess of females among fetuses with the acetazolamide syndrome. Cadmium chloride (and sulfate) produced a similar syndrome in the $\mathrm{S}$ stock rats following day-10 administration. However in this case the defect was virtually confined to the left forelimb. Among these fetuses there was also a significant preponderance of females. Why the limb deformity in either syndrome is so sharply limited to one side and why it more often affects females than males are mysteries. Acetazolamide is an inhibitor of carbonic anhydrase, a zinc metalloenzyme. Cadmium teratogenesis in blocked by simultaneous treatment with zinc (Ferm and Carpenter, '68). That cadmium teratogenesis involves carbonic anhydrase through interference with zinc metabolism, at least in the production of limb defects, is a possibility, but is far from proven. Webb ('72a) found that cadmium reduced carbonic anhydrase activity in the rat testis but suggested that the reduction might be due to altered protein synthesis rather than displacement of zinc by cadmium. Certainly 
further investigations of the relations among carbonic anhydrase, carbonic anhydrase inhibitors, zinc, and cadmium are warranted.

\section{LITERATURE CITED}

Barr, M., Jr. 1972 An animal model for the deficient abdominal muscle syndrome. J. Pediat, $81: 182$.

Berlin, M., and S. Ullberg 1963 The fate of $\mathrm{Cd}^{109}$ in the mouse: an autoradiographic study after a single intravenous injection of $\mathrm{Cd}^{109} \mathrm{Cl}_{2}$. Arch. Env. Hlth., 7: 686-693.

Ferm, V. H., and S. J. Carpenter 1968 The relationship of cadmium and zinc in experimental mammalian teratogenesis. Lab. Inv., 18: 429432.

Ferm, V. H., D. P. Hanlon and J. Urban 1969 The permeability of the hamster placenta to radioactive cadmium. J. Embryol. Exp. Morph., 22: $107-133$.

Flick, D. F., H. F. Kraybill and J. M. Dimitroff 1971 Toxic effects of cadmium: a review. Env. Res., 4: 71-85.

Furst, A., J. E. Cadden and E. J. Firpo 1972 Excretion of cadmium compounds by the rat. Proc. West. Pharmacol, Soc., 15: 55-57.

Kalter, H. 1965 Interplay of intrinsic and extrinsic factors. In: Teratology: Principles and Techniques. J. G. Wilson and J. Warkany, eds. Univ. Chicago Press, Chicago, pp. 57-80.

Layton, W. M., and D. W. Hallesy 1965 Deformity of forelimb in rats: association with high doses of acetazolamide. Science, 149: 306-308.
Mulvihill, J. E., S. H. Gamm and V. H. Ferm 1970 Facial formation in normal and cadmium-treated golden hamsters. J. Embryol. Exp. Morph., 24: 393-403.

Nordberg, G. F., and K. Nishiyama 1972 Wholebody and hair retention of cadmium in mice. Arch. Env. Hlth., 24: 209-214.

Paŕizek, J. 1965 The peculiar toxicity of cadmium during pregnancy: an experimental "toxaemia of pregnancy" induced by cadmium salts. J. Reprod. Fert., 9: 111-112.

Pulido, P., J. H. R. Kagi and B. L. Vallee 1966 Isolation and some properties of human metallothionein. Biochemistry, 5: 1768-1777.

Scott, W. J., R. E. Butcher, C. W. Kindt and J. G. Wilson 1972 Greater sensitivity of female than male rat embryos to acetazolamide teratogenicity. Teratology, 6: 239-240.

Schroeder, H. A., and M. Mitchener 1971 Toxic effects of trace elements on the reproduction of mice and rats. Arch. Env. Hlth., 23: 102-106.

Webb, M. 1972a Biochemical effects of $\mathrm{Cd}^{2+}$ injury in the rat and mouse testis. J. Reprod. Fert., 30: 83-98.

- 1972b Persistence of stored $\mathrm{Cd}^{2+}$ in the livers and kidneys of female rats during pregnancy. J. Reprod. Fert., 30: 99-103.

Wilson, J. G. 1965 Methods for administering agents and detecting malformations in experimental animals. In: Teratology: Principles and Techniques. J. G. Wilson and J. Warkany, eds. Univ. Chicago Press, Chicago, pp. 262-277.

Woo, D. C., and R. M. Hoar 1972 "Apparent hydronephrosis" as a normal aspect of renal development in late gestation of rats. Teratology, 6: 191-196. 